\title{
EXTRAÇÃO DE SEMENTES DE TOMATE SEM FERMENTAÇÃO
}

Flavio Alberto Oliva, Ana Paula Pocaia, Bruna Coelho de Lima, Pedro Veridiano Baldoto, Douglas Fernandes, Layane Oliveira Carvalho, Maycon Vieira Amin

Universidade do Oeste Paulista - UNOESTE, Faculdade de Ciências Agrárias, Presidente Prudente, São Paulo. E-mail: flavioaoliva@gmail.com

\section{RESUMO}

A execução do trabalho ocorreu no laboratório de sementes do Centro de Ciências Agrárias (CCA) e na horta da Universidade do Oeste Paulista (UNOESTE), Presidente Prudente - SP em 2016. No experimento, foram empregados 35 quilos de tomate (Lycopersicon esculentum Mill.), pertencente ao grupo Saladete, cultivar Juliane. As doses de cal hidratada aplicadas foram T1 0,0 $\mathrm{g}, \mathrm{T} 2=50 \mathrm{~g}, \mathrm{~T} 3=100 \mathrm{~g}$ e $\mathrm{T} 4=150 \mathrm{~g}$ respectivamente. As sementes depois de secas foram armazenadas em condições de câmara fria por 14 dias. Em seguida foi avaliado a \% de germinação, índice de velocidade de germinação (IVG) e teste de emergência. A remoção da mucilagem de tomate grupo Saladete, foi mais eficiente com a utilização de $50 \mathrm{~g}$ de cal hidratada, proporcionando reduzir o processo de obtenção de sementes de tomate em dois dias e, aumentando em $25 \%$ o crescimento de plântulas.

Palavras-chave: Sarcotesta; Cal hidratada, Germinação, Altura de Plântuas, Produção

\section{COST OF PRODUCTION AND SUSTAINABILITY OF LETTUCE}

\section{ABSTRACT}

The work was carried out in the seed laboratory of the Center of Agricultural Sciences (CCA) and in the garden of the Universidade do Oeste Paulista (UNOESTE), Presidente Prudente - SP in 2016. In the experiment, $35 \mathrm{~kg}$ of tomato (Lycopersicon esculentum Mill.), belonging to the group Saladete, cultivar Juliane. The doses of hydrated lime applied were $\mathrm{T} 1=0.0 \mathrm{~g}, \mathrm{~T} 2=50 \mathrm{~g}, \mathrm{~T} 3=100 \mathrm{~g}$ and $\mathrm{T} 4=$ $150 \mathrm{~g}$ respectively. The dried seeds were stored under cold chamber conditions for 14 days. Then the germination\%, germination rate index (IVG) and emergency test were evaluated. The removal of Saladete group tomato mucilage was more efficient with the use of $50 \mathrm{~g}$ of hydrated lime, reducing the process of obtaining tomato seeds in two days and increasing the seedling growth by $25 \%$.

Keywords: Sarcotesta; Hydrated lime; Germination, Height of Seedlings; Production

\section{INTRODUÇÃO}

O tomateiro (Lycopersicum esculentum Mill.) é uma hortaliça que dispõe de grande aptidão reprodutiva, além de ser uma planta perene, de estatura arbustiva, e que se procede como uma típica cultura anual, onde sua evolução se expõe na forma rasteira, semi-ereta ou ereta (FILGUEIRA, 2003). Pertencente à família Solanaceae, o tomate tem procedência da zona Andina, na América do Sul, porém foi domesticado no México e introduzido na Europa em 1544. Posteriormente, propagou - se da Europa para Ásia Meridional e Oriental, África e Oriente Médio. Há pouco tempo, o tomate silvestre difundiu - se para as demais partes da América do Sul e México (ALVARENGA, 2004).

Os Estados Unidos são o principal produtor mundial desta cultura, obtendo uma produção de 11 milhões de toneladas, seguido pela Itália com produção de 4,1 milhões de toneladas e 
China, com 3,9 milhões de toneladas. O Brasil é o quinto maior produtor, que atinge aproximadamente 3,8 milhões de toneladas representando uma média de $58,7 \mathrm{Mg} \mathrm{ha}{ }^{1}$, ou seja, o dobro da média da produtividade mundial. Ainda que cultivado em todos os estados em maior ou menor proporção, os grandes produtores são Goiás, Minas Gerais, São Paulo, Bahia e Rio de Janeiro (EMBRAPA, 2017).

O tomate é considerado pelos nutricionistas como um dos frutos mais completos para consumo humano. O tomate de mesa é a terceira hortaliça com maior volume de produção no Brasil. São comercializadas, anualmente, cerca de 1,5 milhões de toneladas dentro do país. Esta cultura é muito exigente em adubação, sendo, portanto, necessário conhecer suas exigências nutricionais, e também os principais sintomas de deficiência nutricional, de modo a corrigi-las para obter o êxito da produção (EMBRAPA, 2017).

Da produção total, 70\% são destinados ao mercado para consumo in natura, o restante é matéria prima para industrialização, com os quais são elaborados diversos produtos, tais como estratos, pastas, molhos, sucos e outros derivados (ALVARENGA, 2004).

A elaboração da muda é uma etapa importante para a condução de uma cultura. Uma muda defeituosa, debilitada, frágil, compromete todo o progresso da cultura ampliando seu ciclo e, em muitos casos, gerando perdas de produção. A propriedade das sementes alcança um conjunto de características que definem seu valor para a semeadura, de forma que o potencial e a performance das sementes tão somente podem ser detectado, de modo consistente, quando é tida a interação das características genéticas, físicas, fisiológica e o vigor que afetam seu potencial de originar plantas de alta produtividade (MARCOS FILHO, 2005).

As sementes de tomate dispõe de um envoltório denominado sarcotesta, que pode estabelecer uma barreira à germinação. Procedimentos como fermentação natural, processos químicos (como ácido clorídrico) e mecânicos podem ser utilizados para a retirada da mucilagem, porém, deve garantir sua qualidade fisiológica (PEREIRA et al., 2000).

A retirada de sementes de frutos carnosos é geralmente feita por processo úmido devido sua ligeireza e competência do procedimento. Sementes de espécies que não possuem mucilagem abrangendo o tegumento estão praticamente aptas para semeadura após lavagem. Contudo, a presença de mucilagem diretamente aderida às sementes exige beneficiamento para a retirada destas. A mucilagem pode atrapalhar a germinação e a evolução da plântula por propiciar o desenvolvimento de microrganismos ou portar substâncias inibidoras de germinação (CARMONA et al. 1994).

A cal hidratada é muito fina e leve e ao ser homogeneizada com água, suas partículas atuam como um lubrificante, pois possuem uma imensa capacidade em reter a água ao seu redor, reduzindo qualquer tipo de atrito (FIDA, 2015). Devido a isso, o uso desse produto pode facilitar a remoção de substâncias mucilaginosas presentes em sementes sem provocar traumas ou danos no tegumento, mantendo o embrião protegido. Além disso, o hidróxido de cálcio apresenta propriedades bactericidas e fungicidas, que evitam o apodrecimento precoce (FIDA, 2015).

Logo, o presente trabalho possui como objetivo avaliar a extração da mucilagem de sementes de tomate com doses crescentes de cal hidratada, com o intuito de acelerar o processo na obtenção das sementes prontas para o campo.

\section{METODOLOGIA}

A metodologia foi fundamentada em experimento inteiramente casualizado, composto por quatro tratamentos, cada um contendo sete repetições. Os tratamentos são T1= Testemunha 0,0 g de cal; $\mathrm{T} 2=50 \mathrm{~g}$ de cal; $\mathrm{T} 3=100 \mathrm{~g}$ de cal; $\mathrm{T} 4=150 \mathrm{~g}$ de cal.

Para tanto, foram empregados 35 quilos de tomate (Lycopersicon esculentum Mill.), pertencente ao grupo Saladete ou Italiano, cultivar Juliane. Estes foram higienizados com auxilio 
de sabão líquido neutro e água corrente. Em seguida, secados com papel toalha e pesados utilizando balança convencional até atingir o peso de $1 \mathrm{~kg}$ para cada repetição. Posteriormente, todos os tomates tiveram suas sementes removidas manualmente respeitando a separação dos tratamentos.

Assim que retiradas as sementes, os tratamentos e suas repetições foram inseridos dentro de béquers de $500 \mathrm{ml}$, onde cada tratamento recebeu sua respectiva dose de cal hidratada, as doses aplicadas foram de $50 \mathrm{~g}, 100 \mathrm{~g}$ e $150 \mathrm{~g}$, exceto a testemunha, a qual foi levada ao processo de fermentação.

O tratamento no qual a dose foi $50 \mathrm{~g}$ de cal, as sete repetições foram misturadas individualmente o máximo possível, e logo após, com o auxílio de uma peneira, enxaguadas em água corrente. Desse modo, retirando totalmente a mucilagem envolta nas sementes e fragmentos da cal. Esse procedimento foi realizado nos demais tratamentos.

Após a lavagem, as sementes foram dispostas sobre um papel filtro para a remoção da água. Permaneceram assim ao longo de três dias, em temperatura ambiente de 24 a $28^{\circ} \mathrm{C}$.

Com o intuito de provocar a fermentação, as sementes provenientes da testemunha foram armazenadas em um béquer de $1 \mathrm{~L}$ e reservada sob uma bancada de laboratório com temperatura ambiente de 24 a $28{ }^{\circ} \mathrm{C}$ durante 72 horas. Concluindo este período, as mesmas foram submetidas à lavagem e secagem conforme os demais tratamentos.

Finalizando o processo de secagem, todos os tratamentos foram pesados, onde foi determinado o peso seco de cada repetição. Em seguida, as amostras foram postas em embalagens de papel Kraft apresentando o peso final de $25 \mathrm{~g}$ e mantidas em condições de câmara fria (UR $=40 \%$ e temperatura média de $17^{\circ} \mathrm{C}$ ) por 14 dias.

\section{Teste de Germinação}

Neste procedimento, 50 sementes por repetição foram introduzidas em caixas acrílicas tipo Gerbox, expostas sobre papel germitest contendo duas folhas por Gerbox, embebidas com água destilada equivalente a 2,5 vezes o peso dos papéis contidos em cada caixa, visando umedecimento uniforme e adequado das amostras.

Os quatro tratamentos tiveram quatro repetições cada, totalizando 200 sementes por tratamento, 800 sementes no total. Em seguida, os Gerbox foram abrigados durante 14 dias em germinador regulado para manter uma temperatura alternada de $20-30{ }^{\circ} \mathrm{C}$, com período de 8 horas de iluminação.

A contagem de germinação foi realizada de acordo com metodologia descrita por Brasil (1992) no sétimo e no décimo quarto dia.

Os parâmetros estipulados para a análise da germinação de plântulas normais foram: porcentagem média de germinação (\%G) e índice de velocidade de germinação médio (IVG) (MAGUIRE, 1962), dado pela fórmula:

$$
\mathrm{IVG}=\mathrm{G} 1+\mathrm{G} 2+\ldots+\mathrm{G} 14 \text {, onde: }
$$

G1 , G2 , G14 = no de plântulas germinadas, computadas na primeira, segunda, ..., e última contagem no 14 으. dia.

\section{Teste de Emergência}

O teste de emergência foi conduzido na horta da universidade, utilizou-se quatro bandejas de poliestireno contendo duzentas células cada, seguidamente demarcadas em quatro partes para determinar as repetições de cada tratamento.

As células foram preenchidas com substrato Carolina ${ }^{\circledR}$, a base de vermiculita e casca de pinus e adicionado $100 \mathrm{~g}$ de $\mathrm{N}-\mathrm{P}-\mathrm{K}$ da fórmula $08-28-16$, posteriormente semeou-se três 
sementes por célula, sendo estas irrigadas três vezes ao dia, no início da manhã, ao meio-dia e no final da tarde. As bandejas estavam em local protegido com sombrite (50\%), foi realizado o teste de emergência até o 14임 dia após a semeadura, sendo averiguado a porcentagem média de plântulas emergidas (\%E) e índice de velocidade de emergência médio (IVE), conforme o cálculo descrito por Popingis (1977):

$$
\mathrm{IVE}=\mathrm{E} 1+\mathrm{E} 2+\ldots+\mathrm{E} 14 \quad \text {, onde: }
$$

$$
12 \quad \text {.... } 14
$$

$\mathrm{E} 1, \mathrm{E} 2, \mathrm{E} 14$ = no de plântulas emergidas, computadas na primeira, segunda, ..., e última contagem no 140 dia.

\section{Crescimento de plântulas}

No 14ㅇ dia após a semeadura foram selecionadas aleatoriamente 15 plântulas provenientes de cada tratamento, totalizando 60 plântulas por tratamento, e com auxílio de uma régua foi mensurado a altura média de plântulas (AP) em centímetros.

\section{RESULTADOS}

A porcentagem de germinação (\%G) média de sementes de tomate do grupo Saladete cultivar Juliane foi numericamente maior nos tratamentos utilizando $50 \mathrm{~g}$ e $100 \mathrm{~g}$ de cal hidratada, o mesmo foi constatado para o índice de velocidade de germinação (IVG), porém não houve diferença significativa para o método utilizado na remoção da mucilagem (Tabela 1).

Tabela 1

\begin{tabular}{ccc}
\hline TRATAMENTO & $\% \mathrm{G}$ & IVG \\
\hline Testemunha & $97,5 \mathrm{a}$ & $22,82 \mathrm{a}$ \\
$50 \mathrm{~g}$ & $99,5 \mathrm{a}$ & $23,21 \mathrm{a}$ \\
$100 \mathrm{~g}$ & $99,5 \mathrm{a}$ & $23,21 \mathrm{a}$ \\
$150 \mathrm{~g}$ & $98,0 \mathrm{a}$ & $22,89 \mathrm{a}$ \\
\hline CV (\%) & 25 & 23 \\
\hline
\end{tabular}

As médias seguidas da mesma letra em cada coluna não apresentam diferença significativa pelo teste Tukey a 5\%.

A altura de plântula (AP) em $\mathrm{cm}$ foi cerca de $25 \%$ superior, quando utilizado cal hidratada para a remoção da mucilagem de tomate, grupo Saladete cultivar Juliane, em relação à testemunha. Os demais parâmetros de porcentagem de emergência de plântulas (\%E) e índice de velocidade de emergência em plantas (IVE) não foram influenciados pelo método de remoção da mucilagem dos tomates, o que é positivo para a produção de mudas (Tabela 2).

Tabela 2 - Valores médios da altura média de plântulas (AP) em cm, porcentagem de emergência de plântulas (\%E), e índice de velocidade de emergência em plantas (IVE) de tomate, grupo Saladete cultivar Juliane ao 14을 dia após a semeadura.

\begin{tabular}{cccc}
\hline TRATAMENTO & AP $(\mathrm{cm})$ & $\% \mathrm{E}$ & IVE \\
\hline Testemunha & $9,25 \mathrm{~b}$ & $100 \mathrm{a}$ & $26 \mathrm{a}$ \\
$50 \mathrm{~g}$ & $12,25 \mathrm{a}$ & $100 \mathrm{a}$ & $26 \mathrm{a}$ \\
$100 \mathrm{~g}$ & $12,25 \mathrm{a}$ & $100 \mathrm{a}$ & $26 \mathrm{a}$ \\
$150 \mathrm{~g}$ & $11,25 \mathrm{a}$ & $100 \mathrm{a}$ & $26 \mathrm{a}$ \\
\hline CV $(\%)$ & 11 & 4,5 & 4,5
\end{tabular}

As médias seguidas da mesma letra em cada coluna não apresentam diferença significativa pelo teste Tukey a 5\%. 


\section{DISCUSSÃO}

É imprescindível a utilização de sementes de alta qualidade, com alto poder germinativo e que produzam plântulas com elevado vigor (PONOBIANCO \& MARCOS - FILHO, 2001). Contudo, a presença de mucilagem intimamente aderida às sementes requer beneficiamento para eliminação destas. A mucilagem pode prejudicar a germinação e desenvolvimento de plântula por favorecer o desenvolvimento de microrganismos ou conter substâncias inibidoras de germinação (CARMONA et al.,1994).

As sementes de tomate possuem um envoltório mucilaginoso chamado sarcotesta, que pode constituir uma barreira à germinação. Métodos como fermentação natural, processos químicos (como ácido clorídrico) e mecânicos podem ser empregados para a remoção da mucilagem, porém, devem assegurar sua qualidade fisiológica (PEREIRA et al., 2000), embora que o uso destes métodos como extração ácida requer maior estrutura e pode onerar ainda mais a produção agrícola, ao passo que os processos de fermentação são mais simples porém expõem as sementes à ação dos microrganismos. Surgindo como alternativa a adoção da cal hidratada, como visto neste trabalho, sendo economicamente viável e aplicável a todos os perfis de agricultores.

Materiais alternativos para retirada da mucilagem são boa opção para o produtor que deseja uma prática economicamente viável e eficiente, principalmente no que diz respeito à germinação de sementes dos genótipos de tomates (MEDEIRO et al., 2016). Como visto neste trabalho, onde a extração da mucilagem pela cal hidratada se mostrou eficiente e por se obter rapidamente a semente desejada, e o processo de fermentação levar três dias para que ocorra a remoção total da mucilagem, além do fato que a semente ficar exposta à ação prolongada de microrganismos.

\section{CONCLUSÃO}

A remoção da mucilagem de tomate pertencente ao grupo Saladete cultivar Juliane foi mais eficiente com a utilização de $50 \mathrm{~g}$ de cal hidratada, proporcionando reduzir o processo de obtenção de sementes de tomate em dois dias e aumentando em $25 \%$ o crescimento de plântulas.

\section{REFERÊNCIAS}

ALVARENGA, M. A. R.; Origem, botânica e descrição da planta. In: ALVARENGA, M. A. R. et al. (Eds.) Tomate: produção em campo, em casa-devegetação e em hidroponia. Lavras: Editora UFLA, p. 15-18. 2004.

BRASIL. Ministério da Agricultura. Regras para análise de sementes. Brasília: SNDA, DNDV, CLAV, 365p. 1992.

CARMONA, R., et al.. Extração química de sementes de gabiroba (Campomanesia adamantium Camb.). Revista Brasileira de Sementes, Brasília, v. 16, n. 1, p. 31-33, 1994. https://doi.org/10.17801/0101-3122/rbs.v16n1p31-33

EMBRAPA. Tomate: Produtividade. Disponível em: < http://www.agencia.cnptia.embrapa.br/gestor/tomate/Abertura.html >. Acesso em: 12 jun. 2017.

FILGUEIRA, F.A.R. 2003. Novo manual de olericultura: agrotecnologia moderna na produção e comercialização de hortaliças. 2 ed. Viçosa, UFV, 412pp. 
FIDA. Conheça os benefícios da cal hidratada. 2015. Disponível em:

http://www.fida.com.br/index.php/conheca-os-beneficios-da-cal-hidratada Acesso em: 30 Ago 2017.

MAGUIRE, J. D. Speed of germination-aid in selection and evaluation for seedling emergence and vigor. Crop science, v. 2, n. 2, p. 176-177, 1962.

https://doi.org/10.2135/cropsci1962.0011183X000200020033x

MARCOS FILHO, J. Fisiologia de sementes de plantas cultivadas. Fealq, 2005.

MEDEIRO, E. L. et al. Germinação de genótipos de tomate sob diferentes métodos de extração de sementes. Anais do Congresso Técnico Científico da Engenharia e da Agronomia, Foz do Iguaçu PR, Brasil, 2016.

PANOBIANCO, M.; MARCOS FILHO, J. Envelhecimento acelerado e deterioração controlada em sementes de tomate. Scientia Agricola, v. 58, n. 3, p. 525-531, 2001. https://doi.org/10.1590/S0103$\underline{90162001000300014}$

PEREIRA, K.J.C.; DIAS, D.C.F.S. Germinação e vigor de sementes de maracujá-amarelo (Passiflora edulis Sims. f. flavicarpa Deg.) submetidas a diferentes métodos de remoção da mucilagem. Revista Brasileira de Sementes, 2000. https://doi.org/10.17801/0101-3122/rbs.v22n1p288-291

POPINIGIS, F. Fisiologia da semente. Ministério da Agricultura, AGIPLAN, 1977. 